\title{
IMPACT OF IDENTITY-ORIENTED LITERATURE EDUCATION ON ADOLESCENTS' INSIGHT INTO THE SELF AND THE OTHER
}

\author{
Peter Grandits \\ Faculty of Education, University of Ljubljana (Slovenia)
}

\begin{abstract}
A mixed-methods quasi-experimental study evaluated the effects of a pedagogical intervention in literature education on Austrian upper secondary high school students' insight into the self and the other. The intervention is based on the newly developed NDR-model, the letters in the abbreviation representing the basic practices of narration, dialogue and response underlying the model. Two cycles of NDR interventions on the identity issues of "happiness" and "relations" were implemented.

An IPA study was conducted to explore how the implementation of the NDR-model of literature education affected participants' learning outcomes (self-understanding and understanding of the other). Qualitative analysis of interview and artefact data suggested that NDR students experienced insight into the self and the other because they were stimulated to engage with literary texts in the context of their personal identities.
\end{abstract}

Keywords: Literature education, scientific study of literature, narrative engagement, insight.

\section{Introduction}

Fialho, Zyngier and Miall (2011) discovered that methods in language arts classes "ha[ve] not been subjected to much empirical research investigation and classroom interventions are generally taken for granted" although "the way classes are conducted can play a role relevant to students' responses to literature" (ibid., 237). The prevalent methods primarily aim at teaching students interpretation and formal analysis, thus distancing students from genuine literary experience (ibid.). Students do not perceive literature as a source of pleasure (Mahling, 2016) and reading as a personally significant process (Sumara, 2002). In addition, emotions and values constitutive of a meaningful reading process (Koopman $\&$ Hakemulder, 2015) are neglected in dominant approaches to literary education.

As literary education fails to encourage students to make literature significant by establishing personally relevant connections, the learning potential of fictional narratives to intersect with and build upon the learners' lives is not fully realized.

The implementation of the NDR-model primarily aims to improve students' narrative engagement and self-insight, trigger meaningful literary response and foster accommodative and transformative learning (Illeris, 2017). The present qualitative study addresses the following research question:

RQ: How does the pedagogic intervention on the basis of the NDR-model of literary education affect participants' learning outcomes (self-understanding and understanding of the other)?

\section{Methods}

A quasi-experimental mixed methods design was implemented (Creswell \& Plano Clark, 2018). First, a Wilcoxon Signed Rank Test revealed statistically significant changes in reading orientations, attentional focus, narrative engagement and self-insight following participation in the educational intervention. In addition, the results of the Mann-Whitney U Test indicated that there was a statistically significant difference in reading orientations, attentional focus, narrative engagement and self-insight between the experimental group and the control group after completion of the intervention. (Grandits, 2021).

Second, quantitative results were used for purposive sampling in the qualitative study and the design of the interview protocol. Third, interviews were conducted, discussions were observed, and artefacts were collected which were analyzed according to the principles of Interpretative Phenomenological Analysis (Smith, Flowers \& Larkin, 2009).

In order to be able to generate a detailed description of the phenomenon in question and to prevent data overload, sample size for this study is small $(\mathrm{N}=70$; seventh-form grammar school 
students). For the qualitative study, stratified purposive sampling (Teddlie \& Tashkkori, 2009) on the basis of the results from the quantitative study was used. The participants were selected on the basis on their scores on reading orientations, reading experiences and self-insight in the pretest. A limited number of participants within the experimental group was selected $(n=6)$.

The qualitative study was conducted within the framework of Interpretive Phenomenological Analysis (IPA; Smith, Flowers \& Larkin, 2009) because this methodology allows us to gain a detailed personal insight into participants' experiences and their interpretations of these experiences. In line with the theoretical underpinnings of IPA, the qualitative study pursues two purposes: (a) to phenomenologically explore participants' descriptions of their experiences of literature education, (b) to hermeneutically understand how the intervention affects the participants' learning outcomes.

Individual face-to-face semi-structured interviews were conducted in a receptive style (Wengraf, 2001). A semi-structured interview protocol containing open-ended questions to encourage detailed responses was used. The questions focused on (a) the general description of the experience, (b) the personal relevance of the experience, (c) agency during the experience, and (d) the detailed description of the learning experience. The interviews were audiotaped and transcribed verbatim. In addition, participants produced experiential reports and artefacts. Discussions were videotaped and transcribed verbatim. All the data were anonymized and treated confidentially. Informed consent was obtained in written form from each participant prior to the implementation of the intervention.

In accordance with the principles of IPA, the following strategies of data analysis were applied to the qualitative data in an iterative cycle until thematic saturation was reached: a. reading and rereading, b. initial noting, c. developing emergent themes, d. searching for connections across emergent themes, e. moving to the next case, f. looking for patterns across cases. Finally, the data are presented in a coherent narrative format, citations from the data are supposed to illustrate each theme.

\section{Results and discussion}

Five main themes were identified from interviews, artefacts and observations. Participants described their experiences of how the intervention affected: (a) engagement; (b) learning practices; (c) self-insight; (d) insight into the other; and (e) text understanding. Themes three and four, which proved to be central to the given qualitative research, are presented below.

\section{Theme 3: Insight into the Self}

Participants distinguished between five effects of the intervention on identity learning. Students' interpretations of the effects on their (a) traits and behavior, (b) attitudes to life, (c) psychological well-being, (d) storied lives, (e) perception of time, and (f) identities as readers and learners will be outlined below.

Bob stated that you could "learn something for yourself, in most cases". In the following, we will present what students said they had learned for themselves during the intervention. First, participants reported that the intervention prompted self-assessment. Students pondered about their action patterns and their character traits as a result of the transaction with the literary text. As a consequence, they discerned a change in behavior and character traits: "[...] I try to partly improve my behavior and my qualities or I simply do not push my negative qualities aside, but I rather really reflect on them, and I consider various perspectives." (Sarah) Reflection raised the awareness for the need of change and self-care: "This clearly showed me that I need to change a bit and that I need to take more care of myself." (Sarah) Bob gave an example of the change, he stopped being very stubborn in everyday encounters. And Mary recounted that she had realized that harmony was essential because her parents had told her that family life made them most happy. Therefore, she tried "not to have my way in stress situations, but I simply stopped and avoided an argument."

Self-assessment also impacted on how students valued their lives. By comparing the tragic life stories of characters with their own stories, they understood the true value of their lives: "It [the intervention] evoked good things, yes, that I'm simply happy with my life as it is." (Sarah)

Second, participants pictured the intervention as transformative as far as their attitudes to life are concerned. These were modified and therefore students gained self-insight:

What did I learn? This is hard to tell, but, I have already mentioned it, concerning happiness, find out what really makes you happy, don't be superficial. Now, personally it was a big advantage for me. (Mary)

Students achieved self-insight by feeling into themselves. This was prompted by the authentic questions posed during the intervention, e.g. 'What makes you truly happy?'. This kind of self-insight had effects on participants' actions: "[...] and maybe I'll do some things or won't do them in the future so that I'm happier, yes, this really made me thinking very much, and, I think, this also influence me, yes." (Mary). Bob had a similar experience:

Yes, in this text about happiness, there were two characters who had a lot of problems, but the ending still was like, ehm, 'Yes, we are fine!' And then I thought for myself, yes, whatever harm happens to me, in the end everything will be alright, and that's what I learned. (Bob) 
Bob's attitude to life changed, he grew more optimistic because of the transaction with the literary text: "Yes, I'm a somewhat pessimistic person as far as my future is concerned, but what I've maybe learnt from the tasks is that I should be hopeful for the future whatever happens."

Third, the intervention also affected the psychological well-being of the participants. Narration enabled the participants to cope with sad events, thus changing their lives. Judith found the writing of the autobiographical story transformative:

No, not depressing because I don't have a problem to tell people about negative events, but I found the task hard when I did it at home, I found it really difficult to write about it or it took me quite long because I needed breaks all the time. But I have benefitted, I feel better when I think about it now. [...] Telling the personal story, the self-experience, it really helped me, I can cope with it now, it was like a therapy. (Judith)

Other students confirmed this purging effect: "For me, it was very important to write the story in the beginning, that sad experience that I had, in order to come to terms with it." (Mae) Mary highlighted the consequences of the disclosure of repressed life episodes: "[...] that you are thankful in the first place, that it doesn't come to that anymore, and, that you'll maybe change your behavior because of it."

Fourth, participants experienced an effect on their personal life stories. Past events were recalled and reflected when students told their personal stories: "[...] It [the past] was called to mind and I could think about it once more." (Bea) Not only recent memories were remembered, but also distant events: "I also thought of things that had happened long ago, which I perhaps repressed because they were bad, and then I took them up again [...], and I was thankful in the first place that, yes, things are not like that anymore, yes, and maybe I'll change my behavior" (Mary) Disturbing memories were revived in the present, they aroused feelings and had future implications on students' behavior. For example, Sarah realized through the identity task that she had been too submissive in the past, she disapproved of her behavior and decided to change it. She stated that it was the intervention that "made me realize my past, and where I went wrong and what I could have done better". Recall of the relevant episodes of the life story also gave participants the opportunity to account for how they acted in the past.

In addition, the evocation of memories raised participants' awareness of the fact that past experiences shaped their present being. This awareness was regarded beneficial for the future as life was perceived less superficially.

Fifth, students also reported an influence on their time perception, they became aware of the temporality of their being. They realized that time perception was closely linked to their storied lives. When telling their personal stories, the past was reflected in the present, and this present reflection provided students with additional future opportunities. Past memories were evoked during the present transactional engagement: "Yes, I realized what I had experienced in my short life, [...] and, yes, I found it nice that I could account for the past yet again, from childhood till now, so that you can recall the past." (Judith) Participants experienced the effect that the temporal distance between past and present was bridged during the process of remembering, discontinuities were overcome. In addition to personal memories, cultural experiences of the past were recalled in the intertextual reading of the literary texts.

The present experience that the students linked up with their past had implications for the future. Participants explained that a changed attitude to life, which had become apparent in new life concepts, shaped their perception of the future. Bea discovered that she had a different perspective on problems although having read the book did not help her solve the problem. Mary realized that the intervention had offered her future possibilities for action. She was taught that she was agentive and that she could change her behavior. Awareness of the past made Sarah recognize the need for change.

Sixth, the intervention also changed the participants' identities as readers. Bea stated that she had not been interested in reading before the intervention, but as a result of the intensive engagement with the literary text she enjoyed reading. Therefore, she identified the future objective of adopting a new reading attitude. In addition, modified orientations to reading were reported: "I think I would read the book with a different attitude now." (Mary) In the same vein, we can sense a change of reading orientation in Judith's testimony.

Yes, I should not see reading ..., for example, because I didn't enjoy it for some time, because in the past I really enjoyed reading, I should not see it in a negative light, but, that I should try it again and maybe engage more with the books. (Judith)

Judith adopted a new approach to reading which was grounded in perseverance. She had realized that high engagement was essential for the learning outcome. We can conclude that intensive engagement could facilitate a change in reading orientations. Mae also noticed a better overall performance at school because of the change in reading attitude.

Participants also remarked on the insight into the Self on the meta level. Emotional resistance was regarded a precondition for change. Learning was experienced as transformative: traits, actions, attitudes, psychological condition, life stories and habits were changed due to the intervention. Although they answered the question in the negative whether the intervention fundamentally changed them as a person, participants reported changes in self-understanding, in their psychological condition, in their storied lives, in their perception of time, and their identities as readers and learners. They actively 
increased their capacity to rethink life. In the discussions, participants additionally mentioned changes in their relational identities.

Participants agreed that the reported changes could be traced back to the intervention. No other factors were detected. Moreover, students repeatedly stated in their experiential reports that were written three months after the intervention that the lessons had a lingering effect. The ideas triggered by the intervention had stayed with them by then. Students also highlighted a better retention of the learning outcome. Sarah concluded in her report that students gained a lot of new insights about themselves, they got to know literature better, they got to know their classmates better, and they escaped the daily school routine. Despite their spontaneous negative answers to the question whether fundamental changes had taken place, we can infer from the interviews, artefacts and observations that transformative learning occurred as an effect of the intervention.

\section{Theme 4: Insight into the Other}

Mae's description of how participants experienced the insight into the relationships with others is representative: "I don't know, I just think I will treat people differently than before." Bob, for instance, decided to respond to significant Others in a more friendly way because he had learned to empathize with characters during the intervention. Mary expounded on the insight into the Other:

It was very interesting, I think, to get to know close people better once again, and I think that the question what people think about happiness is very interesting though very personal. If people tell a story ... what really makes them happy, and, as I said, that really influenced me. First, how I see these people, and second, how I treat them, and, what I maybe want to do to make others happy. (Mary)

Insight of the other was yielded by listening to significant Others telling their personal stories. Identity work in phases one and two influenced the participants' perception of others, their response to others as well as the actions towards others. Changes in students' perception of their relations could be partly traced back to a change of life concepts. Affective behavior toward others was also altered. Mae, for instance, acted more emotionally expressive towards others after the intervention.

A further effect on the insight into the Other was that people were evaluated differently: "In any case, I'll be able to judge people differently from what I thought before" (Judith). Higher tolerance for others was shown, participants had become more unwilling to change others and interfere with others' beliefs: "Yes, well, I'll try to let people be the way they are, and I'll try not to think ill of them somehow. [...] Everybody can decide for themselves, and, it doesn't concern me. And, I think, I've learned this only recently." (Judith). In conclusion, general insight into human nature was reported. Others were perceived and judged differently, and as a consequence, actions towards the others changed.

Adopting different views was considered a means to insight into the Other: "It was interesting that, I've said this before, that there were different opinions, and that you allow these different opinions, and that you change your own opinion a bit or that you can rethink things, yes." (Mary) Acceptance of alternative views was facilitated by putting yourself in the other's position: "It made me clear that I had to see things from different perspectives because I think, well, I tried this before, but through it [the intervention] you got a much better picture of it, you see things differently." (Sarah). To sum up, participants reported a better understanding of the other through the change of perspective.

The intervention also had ethical implications. First, students reconsidered ethical norms:

"Well, I wouldn't draw a clear line between good and evil anymore because there are people who somehow seem, well, not bad, but nasty, but there is a reason why they are that way, and therefore I wouldn't divide people simply in two groups, in good and evil, but you have to question these categories." (Judith)

Ethical reflection of that kind was caused by a thorough analysis of characters' traits and reasons for their actions. Students held that both the text's structure and the intensive engagement with the text provoked ethical thinking.

In addition, participants discovered the harmful nature of prejudices. They also felt a moral obligation to voice their own opinions and to defend their opinions, but also to scrutinize others' opinions and to accept them.

In conclusion, participants reported a change in perceptions and evaluations of significant Others and in actions towards these significant Others. Identity work and the transactions in personal response to the literary text were seen as causing these changes. In addition, different views in external dialogues facilitated insight into the Other. Finally, the intervention did not only affect personal relationships. Ethical knowledge about norms, obligations and imperatives was generated as well.

\section{Conclusions}

It can be concluded from the qualitative results that the intervention based on the NDR-model affected participants' learning outcome (self-insight, insight into the other).

There is empirical evidence for the insight into the Self. In the literature, the following effects of reading literary texts on identity are postulated. First, identity can be aesthetically experienced during 
reading (Kuiken, Miall \& Sikora, 2004). During the transactional process, personal connections were established. Students responded both cognitively and affectively to the text in aesthetic experience. They imagined the world of the text and were transported to this imagined world. During the transactions, attention was mostly balanced between the world of the text and the world of the reader. It could be proven that aesthetic experience is a precondition for insight into the self. Second, knowledge about identity is discussed and performatively produced (Krammer, 2013). Participants reflected and co-reflected on their traits, their behavior, their attitudes to life, their habits, and their storied lives in response to reading literary texts, and by reflecting identity, they generated new knowledge about identity. Third, reading literature has the potential of transforming the reader's identity (Ricoeur, 1991). Behavior, attitudes, psychological condition, personal stories, time perception, and identity as readers and learners were changed due to the intervention. Fourth, literature affects personal identity in its temporal dimension (Ricoeur, 1992). The students experienced themselves in their temporality. They realized how past, present and future are interrelated. New possibilities of agency were opened up by learning how to apply the learning outcome to personal life. In addition, participants realized that the personal story could provide continuity. Narrative change and consolidation were experienced as indicators of development. Fifth, literature affects social identity negotiations in situated contexts (Beach, Johnston \& Thein, 2015). Dialogue allowed insight into how identity was conditioned by relationships to significant Others. Thus, both understanding of the Self and the Other was enhanced. Sixth, literature emphasizes the ontological status of identity as cultural fiction (Krammer, 2013). Participants' recalled and reflected their storied lives, thus they became aware of the fictional nature of the story and the selective mechanism that generates the story.

The qualitative study also proved that the intervention yielded insight into the other. Changes in the perception and evaluation of others and in the actions towards others were evident. In addition, ethical norms that regulate social living together were reconsidered.

The findings of the qualitative study corroborate the quantitative results that both insight into the Self and insight into the Other were promoted by the intervention. In conclusion, the intervention based on the NDR-model is purposeful as it met the principal learning objective set out at the beginning of the design process. The intervention fostered students' learning about themselves and others.

\section{References}

Beach, R., Johnton, A. \& Thein, A.H. (2015). Identity-focused ELA teaching: A curriculum framework for diverse learners and contexts. New York. Routledge.

Creswell, J.W, \& Plano Clark, V.L. (2018). Designing and conducting mixed methods research. $3^{\text {rd }}$ ed. Thousand Oaks, CA: Sage.

Fialho O., Zyngier S., \& Miall, D. (2011). Interpretation and experience: Two pedagogical interventions observed. English in Education, 45(3), 236-253.

Grandits, P. (2021, March). Impact of identity-oriented literature education on adolescents' attentional focus, modes of engagement and self-insight. Paper presented at the INTED 2021.

Illeris, K. (2017). How we learn: Learning and non-learning in school and beyond. 2nd ed. Oxon: Routledge.

Koopman, E.M., \& Hakemulder, F. (2015). Effects of literature on empathy and self-reflection: A theoretical-empirical framework. Journal of Literary Theory 9(1), 79-111.

Krammer, St. (2013). Identität und Performanz: Aspekte der Literaturlehr- und -lernforschung. (Unpublished habil. dissertation). University of Vienna.

Kuiken, D., Miall, D., \& Sikora, S. (2004). Forms of self-implication in literary reading. Poetics Today, 25(2), 171-203.

Mahling, M. (2016) Lesepraxis von Kindern und Jugendlichen: Die Bedeutung von Familie, Schule und Peers für die Beschaffung und Nutzung von Lesestoffen. Berlin: de Gruyter.

Ricoeur, P. (1991). Narrative Identity, Philosophy Today, 35(1). 73-81.

Ricoeur, P. (1992). Oneself as another. Chicago: University of Chicago Press.

Smith, J., Flowers, P., \& Larkin, M. (2009). Interpretative Phenomenological Analysis: Theory, Method and Research. London: Sage.

Sumara, D.J. (2002). Why reading literature in school still matters: Imagination, interpretation, insight. New York: Routledge.

Teddlie, C., \& Tashkkori, A. (2009). Foundations of mixed methods research. Thousand Oaks, CA: Sage.

Wengraf, T. (2001). Qualitative research interviewing: Biographic Narratives and Semi-structured Methods. London: Sage. 